\title{
Uma análise sobre consumo e apropriação de literatura entre estudantes
}

\author{
An analysis of literature consumption and appropriation among students \\ Un análisis sobre el consumo y apropiación de literatura entre estudiantes \\ André Carlos Moraes* \\ Ana Cláudia Gruszynski ${ }^{* *}$
}

\section{Resumo}

Análise e problematização de dados empíricos de leitura que integraram pesquisa com 667 estudantes universitários de primeiro ano. Os alunos responderam a questionários e foram entrevistados sobre as formas pelas quais entraram em contato com as obras literárias indicadas ao vestibular. Observou-se significativa fragmentação e alternância entre suportes de conteúdo. Os dados permitem formular a hipótese de que o contato dos estudantes com o texto literário, seja de forma normativa ou por fruição, atravessa plataformas em trajetos de apropriação altamente personalizados em meio a um conjunto de soluções e alternativas para o qual, aqui, se utiliza a metáfora da nuvem.

Palavras-chave: leitura literária, apropriação de texto, suportes, plataformas.

\section{Abstract}

This paper analyzes and problematizes the empirical data collected from a group of 667 firstyear university students for a study on reading. The students answered questionnaires and were interviewed about the ways in which they came into contact with the literary works indicated for the entrance exam. Significant fragmentation and alternation between content media was observed. Based on this data, we hypothesize that the students' contact with the literary text, whether in a normative way or for enjoyment purposes, crosses platforms in highly personalized paths of appropriation among a set of solutions and alternatives for which the metaphor of the cloud is employed.

Keywords: literary reading, appropriation of text, supports, platforms.

\section{Resumen}

Análisis y problematización de datos empíricos de lectura que integraron investigación con 667 estudiantes universitarios de primer año. Los alumnos respondieron a cuestionarios y fueron entrevistados sobre las formas por las cuales entraron en contacto con las obras literarias indicadas en el exámen de acceso a la universidad. Se observó una significativa fragmentación y alternancia entre soportes de contenido. Los datos permiten formular la hipótesis de que el contacto de los estudiantes con el texto literario, sea de forma normativa o por fruición, atraviesa plataformas en trayectos de apropiación altamente personalizados en medio de un conjunto de soluciones y alternativas para el cual, aquí, se utiliza la metáfora de la nube.

Palabras clave: lectura literaria, apropiación de texto, portadores, plataformas.

\footnotetext{
* Doutor em comunicação e informação pela Universidade Federal do Rio Grande do Sul, Porto Alegre, RS, Brasil. orcid.org/0000-0002-2473-9286. E-mail: andrecmoraes@uol.com.br.

** Doutora em comunicação social e professora da Universidade Federal do Rio Grande do Sul, Porto Alegre, RS, Brasil. orcid.org/0000-0001-8840-0153. E-mail: anagru@gmail.com.
} 


\section{Suportes e narrativas}

O presente artigo apresenta e analisa dados quantitativos e qualitativos sobre formas de contato e apropriação de literatura obtidos junto a uma amostra delimitada de estudantes. São discutidos resultados de uma pesquisa de doutorado da área de Comunicação que enfocou estratégias de leitura e estudo de jovens universitários, trabalho que estava ligado a um projeto de investigação mais amplo sobre conteúdo multiplataforma. Aliando conceitos teóricos a este aporte empírico, buscamos, aqui, oferecer um vislumbre de diversas trajetórias e experiências de leitura, algumas delas com propósitos pragmáticos, outras erguidas a partir de preferências e conveniências pessoais dos alunos, e de como estes elementos observacionais, ainda que limitados, podem contribuir para a compreensão das novas modalidades de apropriação do texto literário.

A pesquisa observou táticas de estudo e leitura entre 667 estudantes de primeiro ano da Universidade Federal do Rio Grande do Sul (UFRGS) entre 2011 e 2016, tanto através de formulários autopreenchidos quanto em 31 entrevistas semiestruturadas por telefone. ${ }^{1}$ Como indicador principal, foi adotada a lista de obras obrigatórias para a prova de Literatura do vestibular. Trata-se de uma relação de 12 títulos das literaturas brasileira e portuguesa que os candidatos devem ler. Buscou-se inquirir quais obras os estudantes haviam lido na íntegra e quais suportes haviam adotado, tanto para leitura integral quanto para consultas ou acesso a resumos. As definições dessa amostra e desse indicador específico seguem pressupostos teóricos apresentados sinteticamente a seguir.

Há autores que, ao abordar o tema das transformações do livro na era eletrônica, dão atenção especial ao comportamento das novas gerações. Para o crítico e ensaísta norte-americano Sven Birkerts:

A absorção da cultura impressa pelas tecnologias eletrônicas continuou a grande velocidade, e confrontamos as consequências em toda parte. Para começar, jornais estão em crise, suas circulações despencando à medida que velhos leitores desertam para fontes on-line de áreas específicas (parte do fenômeno de nicho) e jovens leitores deixam de aderir como novos consumidores. Estes leitores potenciais já têm novas preferências condicionadas e novos reflexos para lidar com informação - condicionamento que, não surpreendentemente, afeta também a leitura de livros (Birkerts, 2006, p. 238, tradução nossa).

O norte-americano Jeff Gomez, discutindo o livro eletrônico, identifica o que chama de geração download:

Para eles, as noções de tempo e espaço foram quase totalmente apagadas: toda comunicação é instantânea e toda informação está a apenas um clique de distância. Mesmo objetos outrora físicos, como gravações e livros - para não falar em programas de tevê e filmes -, foram estourados em pedacinhos e convertidos em pequenas fatias e nacos digitais. E no lugar de tentar colar tudo de novo, a Geração Download está catando no meio dos cacos, interagindo com cada pedaço de entretenimento literalmente bit por bit (Gomez, 2008, p. 71-72, tradução nossa).

Nos dois trechos citados, os autores fazem, de formas diferentes, um duplo jogo de relações. Relacionam as novas gerações com as tecnologias de informação e, a partir dessa mediação, abordam sua relação com os livros. Esse paralelismo também é apontado por teóricos brasileiros. Em um dos ensaios da coletânea A mídia impressa, o livro e as novas tecnologias, Arlindo Machado afirma:

A passagem de uma cultura do texto verbal para uma cultura do audiovisual e da multimídia, quando não é sumariamente condenada pelos analistas, é pensada pela maioria deles numa perspectiva exclusivamente pedagógica. As novas gerações raciocinam esses analistas - resistem cada vez mais ao livro impresso e às formas escritas de fixação do pensamento (Machado, 2002, p. 114).

Uma das leituras possíveis das observações dos três autores acima seria que os leitores jovens são vistos como a linha de frente de uma transformação dos hábitos culturais. Se, por um lado, estão em maior contato com novas tecnologias e meios de distribuição de informação, por outro, há quem

\footnotetext{
${ }^{1}$ Os procedimentos técnicos serão detalhados na próxima seção.
} 
aponte, como indicam Machado (2002) e Birkerts (2006), uma mudança na relação com os livros. Nestas referências teóricas, fundamentou-se a relevância de uma pesquisa empírica com jovens.

O indicador primário adotado utiliza um conceito apresentado por Ana Cláudia Silva Fidelis na tese Do cânone literário às provas de vestibular: canonização e escolarização da literatura, apresentada em 2008 no Instituto de Estudos da Linguagem da Universidade Estadual de Campinas. A autora aborda os cânones literários, definidos por ela como "textos ou escritores autorizados, reconhecidos por uma tradição ou que passam a fazer parte dela" (Fidelis, 2008, p. 11), na perspectiva de sua adoção pelas escolas e universidades. Identifica nas listas de leitura obrigatória uma forma de cânone:

Em seus exames de seleção, uma parcela significativa das instituições públicas de nível superior adota a indicação prévia de escritores e obras para leitura a ser avaliada nas Provas de Língua e Literatura. Essa indicação prévia (geralmente anunciada no início de cada ano letivo) lista, então, uma série de obras a serem lidas durante o ano por alunos de Ensino Médio que pretendem se submeter aos exames de seleção destas instituições; daí adveio a nomeação adotada no ambiente escolar - listas de Vestibular. A partir desta prática, as Listas de Vestibular passaram a instituir as leituras feitas pelos estudantes de Ensino Médio, reapresentando no ambiente escolar um outro recorte canônico (Fidelis, 2008, p. 96).

A pesquisa propôs a adoção das listas de leitura obrigatória como indicador justamente por essa dimensão. As listas representariam uma forma de texto sancionado pela instituição de ensino superior, funcionando, na prática, como uma instância de canonização. É a relação dos estudantes com este corpo de textos literários oficialmente chancelados que o trabalho empírico buscou observar.

Outro aspecto intrínseco às listas de vestibular e determinante para sua funcionalidade como indicadores na pesquisa é o fato de serem em grande parte compostas por textos narrativos. Interessava compreender narrativa como um gênero textual passível de ensejar, principalmente, certos regimes de engajamento - tanto em termos de envolvimento com a leitura quanto em questões de suporte de acesso.

O britânico John B. Thompson, discutindo os tipos de conteúdo textual que podem ou não ser associados ao livro impresso e ao texto eletrônico, lista em Books in the digital age uma forma que ele nomeia de narrativa:

Esta é uma forma de conteúdo que é articulada como uma história estendida com um início, um enredo de algum tipo e um final ou algo assim. A forma narrativa não é um molde rígido e definitivo, mas é uma estrutura com a qual todos estamos intuitivamente familiarizados. É uma estrutura normalmente usada na ficção, mas não restrita ao reino ficcional: também é usada em não-ficção, por exemplo em biografias e autobiografias, ou no tipo de redação histórica que conta uma história sobre o passado, sobre eventos específicos ou personagens ou sobre um desenvolvimento histórico mais amplo (Thompson, 2008, p. 325, tradução nossa).

Na análise de Thompson, que buscava, sobretudo, identificar gêneros textuais em transposição para o meio eletrônico, a forma que o autor identifica como narrativa era uma das que ele considerava menos portáveis para plataformas não impressas, devido à maior dificuldade de leitura de textos longos em tela (Thompson, 2008, p. 327). Vale lembrar que a observação dele foi feita em um contexto anterior ao lançamento ou popularização de alguns dispositivos móveis usados para leitura, como o Kindle da Amazon, o iPad da Apple e os smartphones em geral.

De maneira semelhante, o crítico norte-americano Sven Birkerts discute rumos da cultura do livro, em The Gutenberg Elegies (2006), adotando como ponto central o gênero narrativo do romance:

Eu vou me confinar ao romance literário que, para mim, representa a leitura em sua forma mais pura. E o que me interessa aqui não são as encarnações superficiais do ato - lutas relutantes com romances que não temos vontade de ler - mas seus envolvimentos mais idealizados (Birkerts, 2006, p. 79, tradução nossa).

Esta posição do autor ganha relevo em função de seu entendimento sobre o papel da narrativa: O conhecimento humanístico, como sugeri mais cedo, difere dos tipos mais instrumentais de conhecimento no que ele, em última análise, busca formatar uma narrativa 
compreensível. É, em outras palavras, a criação e expansão de contextos significativos. Tecnologias de mídia interativas são, ao menos em um sentido, anticontextuais. [...] O enfoque multimídia tende inevitavelmente à multidisciplinaridade. O efeito positivo, claro, é a criação de novos níveis de conexão e integração; mais e mais variáveis são trazidas para a equação. Mas o perigo deveria ser óbvio: o horizonte, o limite que deu definição para partes da narrativa, vai desaparecer. A equação em si vai perder o sentido através do acúmulo de variáveis (Birkerts, 2006, p. 137-138, tradução nossa).

Assim como Thompson, Birkerts identifica uma forte associação do gênero narrativo (em especial o romance literário) com a forma do livro impresso. Este conjunto, por sua vez, seria num nível mais profundo organizado de forma muito diferente daquela lógica multimídia. O autor defende, em última análise, que o processo lento e paciente da imersão em leitura narrativa tem um impacto psicológico e até metafísico sobre o leitor (Birkerts, 2006, p. 80-81), o que ele sintetiza em um axioma: “O que a leitura faz, em última análise, é manter viva a excitante e perigosa ideia de que a vida não é uma sequência de momentos vividos, mas um destino" (Birkerts, 2006, p. 85, tradução nossa).

Em um nível menos profundo do que a preocupação de Birkerts, há uma longa tradição teórica que assume abstratamente uma oposição entre o livro e as mídias eletrônicas, começando pela clássica afirmação de Marshall McLuhan de que "todos os efeitos da tecnologia tipográfica encontram-se agora em forte oposição à tecnologia eletrônica" (McLuhan, 1972, p. 311). É uma posição similar àquela já citada de Arlindo Machado (2002). Outro conceito que mobiliza interações de suporte ou plataforma é o das mixologias, proposto por Nízia Villaça (2010):

a tendência contemporânea da desfronteirização dos saberes e transversalidades dos códigos narrativos [...], construindo um lugar dinâmico onde o hegemônico e o alternativo se enfrentam para a constituição de uma cultura e de uma identidade que não sejam fruto apenas da lógica do consumo e do entretenimento (Villaça, 2010, p. 217-218).

Villaça analisa produtos e esferas da comunicação para identificar o que, no trecho acima, chama de "transversalidades". A autora acrescenta: "Os editores mudam as estratégias em direção ao entretenimento, à autoajuda, a discos e vídeos, reticentes diante dos livros de grande formato", sinal de uma "convergência de meios" onde "já não se organiza o saber tendo o impresso como foco ordenador" (Villaça, 2010, p. 41).

O trânsito entre as narrativas contidas nos livros e aquelas dos outros meios ou suportes, portanto, é uma questão de pesquisa repetidamente abordada em trabalhos recentes. A complementaridade, convivência ou substituição de uma mídia narrativa pela outra motivam análises e, mesmo, preocupações de diversos matizes teóricos. Vem daí parte do interesse que motivou o trabalho de campo abordado neste artigo.

\section{Levantamento com leitores}

Para cotejar os diferentes modelos conceituais com o mundo empírico dos leitores, o levantamento procurou observar o fluxo de interesse pelas narrativas junto a uma comunidade segmentada. As subseções a seguir trazem procedimentos metodológicos, apresentam e discutem dados obtidos no trabalho de campo.

\section{Procedimentos metodológicos}

A observação com leitores envolveu um ciclo quantitativo e um qualitativo e foi realizada com estudantes de primeiro ano da UFRGS em três rodadas, nos anos de 2011, 2014 e 2016. A pesquisa foi balizada pelo Comitê de Ética em Pesquisa da universidade (CEP UFRGS), ${ }^{2}$ e

\footnotetext{
${ }^{2}$ Registro do projeto no sistema de pesquisa UFRGS: 27.354. CAAE do projeto: 3212241 4.6.0000.5347. Parecer 770.029 do CEP UFRGS, aprovado em 28 ago. 2014.
} 
realizada em três etapas cronologicamente espaçadas para permitir uma leitura dos resultados longitudinal, ou seja, ao longo de um eixo de tempo.

No procedimento quantitativo, foram distribuídos formulários preenchidos individualmente em sala de aula a um total de 667 alunos, que foram desse modo questionados sobre quantos e quais livros das listas obrigatórias do vestibular haviam lido. O formulário também inquiria sobre as formas de contato empregadas tanto para leitura integral quanto parcial, além de incluir questões sobre formas de lazer em geral e outros hábitos de leitura à parte a escolar ou acadêmica. Havia campos para que os respondentes assinalassem categorias de contato com os títulos que não incluíam conteúdo integral, tais como filmes ou documentários, resumos e aulas ou grupos de estudo. ${ }^{3}$

Foram distribuídos 263 formulários em 2011, 269 em 2014 e 135 em 2016, entre os cursos de Medicina, Direito, Psicologia, Engenharia Civil, Ciência da Computação, Letras, Biologia, Veterinária, Jornalismo, Publicidade e Relações Públicas. Foi escolhido para amostragem um curso de cada grande área da Capes, selecionados a partir da maior densidade de candidatos por vaga no vestibular de 2011. Houve o acréscimo dos cursos de Comunicação Social (Jornalismo, Publicidade e Relações Públicas), área da qual a pesquisa era nativa.

No ciclo qualitativo, foram realizadas 31 entrevistas telefônicas semiestruturadas com alunos que haviam respondido ao formulário. A finalidade desta etapa era dupla, servindo tanto para confirmar dados quanto funcionar como triangulação, ou seja, oferecer uma segunda via metodológica de observação. As entrevistas foram feitas por telefone para otimizar os recursos e atender a uma recomendação do Comitê de Ética, que aconselhou que a pesquisa fosse realizada em condições que não onerassem os estudantes com preocupações de deslocamento e segurança. A quantidade de entrevistas também foi balizada pelo CEP. Os alunos entrevistados foram escolhidos tanto através de especificidades das fichas de preenchimento ${ }^{4}$ quanto pela própria disponibilidade, já que houve uma adesão voluntária bastante reduzida neste ciclo. Outra preocupação foi ouvir uma quantidade de alunos uniformemente distribuída pelos cursos amostrados.

Uma observação cautelar é necessária em relação à mescla de técnicas e metodologias. Mesmo no levantamento quantitativo, a amostragem adotada é do tipo de conveniência ou não probabilística. Não se trata de um estudo com abrangência estatística e demográfica, não sendo possível generalizar as conclusões. Os resultados não são representativos da comunidade mais ampla de leitores estudantis brasileiros, nem do grupo menor dos alunos da UFRGS, ou mesmo da totalidade das turmas dos calouros daquele período observado. A análise, tanto em relação aos dados tabuláveis quanto às entrevistas, é feita de forma qualitativa, em busca de relações, não indicadores demográficos. Não há como extrapolar as conclusões para um grupo maior do que o observado, porém se defende a relevância da observação ao vislumbrar as dinâmicas de envolvimento desta amostra delimitada de alunos com o texto literário e os suportes de leitura.

\section{Dados de leitura}

A apresentação e a análise dos resultados da pesquisa começam pelos dados da Tabela 1, que traz as médias de leitura integral dos 12 títulos da leitura obrigatória do vestibular da UFRGS por parte dos estudantes das turmas amostradas nos anos de 2011, 2014 e 2016. Como se trata de amostragens com composições diferentes (nem todos os cursos foram amostrados em cada rodada), é útil visualizar inicialmente as rodadas em separado, o que serve metodologicamente para avaliar a coerência entre os dados obtidos - procedimento importante, já que não se trata de amostra probabilística.

\footnotetext{
${ }^{3}$ Uma apresentação pormenorizada pode ser vista em Moraes (2017).

${ }^{4}$ Buscou-se ouvir estudantes cujas fichas de preenchimento fossem representativas de extremos (por exemplo, número muito elevado ou muito reduzido de leituras em livro ou em meio eletrônico; nenhum livro da lista lido, ou todos os livros lidos; quantidade reduzida de suportes empregados ou, pelo contrário, quantidade expressiva de suportes) e também aqueles que, estatisticamente, se mostrassem representativos da média (exatamente dentro do intervalo médio de leitura, ou do uso de suportes).
} 
Tabela 1 - Comparação de títulos lidos (2011 a 2016)

\begin{tabular}{l|ccc}
\hline \multicolumn{1}{c}{ Ano } & 2011 & 2014 & 2016 \\
\hline Mediana & 7 & 7 & 6 \\
Média aritmética & 6,49 & 6,83 & 6,01 \\
Moda & 9 & 12 & 7 \\
Desvio padrão & 3,51 & 3,64 & 3,32 \\
\hline
\end{tabular}

Fonte: dados da pesquisa.

Lembrando que as listas de vestibular da UFRGS possuem 12 títulos, os números da Tabela 1 apresentam coerência ao longo das três rodadas ao conter médias parecidas. A mediana (o valor geometricamente no centro do grupo de dados) é a mesma em 2011 e 2014, com ligeira queda em 2016. As médias aritméticas também são muito semelhantes. Há desvios padrão quase idênticos, indicando que a maioria dos estudantes amostrados não se desviou muito das médias de leitura. A maior oscilação é na moda (o valor mais repetido em cada grupo). Nesse caso, pode haver maior influência da composição das turmas. Nota-se que na rodada de 2014, por exemplo, a quantidade mais recorrente era de 12, ou seja, de alunos que haviam lido todos os títulos. Porém, a moda não chegou a afetar significativamente as médias naquele ano, já que tanto a média aritmética quanto a mediana seguiram dentro do intervalo observado nos outros anos.

Feita a ressalva das diferentes composições das turmas observadas em cada rodada e das semelhanças ou disparidades entre elas, o Gráfico 1 traz os totais de leitura dos livros da lista de vestibular da UFRGS declarados pelos 667 alunos da mostra.

Gráfico 1 - Totais de leitura dos livros da lista da UFRGS (2011 e 2016)

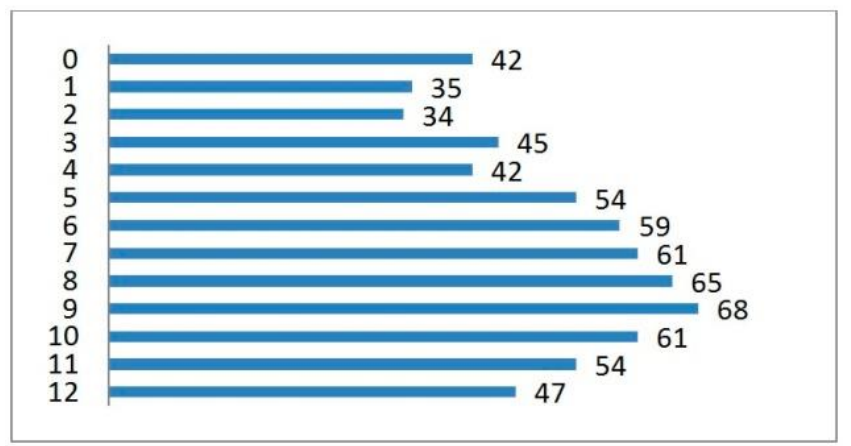

Fonte: dados da pesquisa

Como se vê no Gráfico 1, menos alunos assinalaram ter lido entre zero e quatro obras durante a preparação ao vestibular, enquanto o grupo mais numeroso leu 9 títulos. $O$ Gráfico 1 traz uma forma diferente de visualizar os dados que estão na Tabela 1. Em conjunto, ambos servem aqui, principalmente, para dar uma compreensão geral do comportamento de leitura dos estudantes pesquisados. O tema principal do artigo, a relação dos alunos com o material lido propriamente dito, começa a ser vislumbrado nas Tabelas 2, 3 e 4. Ali, constam as quantidades de leitura integral em 2011, 2014 e 2016 discriminadas para cada uma das 12 obras da lista obrigatória da UFRGS em cada ano. 
Tabela 2 - Ranking de obras mais lidas na íntegra na mostra de 2011

\begin{tabular}{|c|c|c|c|}
\hline Ordem & Obra & Leitores & $(\%)$ \\
\hline $1^{0}$ & Contos de Machado de Assis & 218 & $83 \%$ \\
\hline $2^{\circ}$ & José de Alencar - Lucíola & 187 & $71 \%$ \\
\hline $3^{\circ}$ & Machado de Assis - Memórias Póstumas de Brás Cubas & 183 & $70 \%$ \\
\hline $4^{\circ}$ & Rubem Fonseca - Feliz Ano Novo & 159 & $60 \%$ \\
\hline $5^{\circ}$ & Dias Gomes - O Pagador de Promessas & 153 & $58 \%$ \\
\hline $6^{0}$ & Poemas de Álvaro de Campos - Fernando Pessoa & 152 & $58 \%$ \\
\hline $7^{0}$ & Cyro Martins - Porteira Fechada & 147 & $56 \%$ \\
\hline $8^{\circ}$ & Eça de Queirós - O Primo Basílio & 132 & $50 \%$ \\
\hline 90 & Basílio da Gama - O Uraguai & 127 & $48 \%$ \\
\hline $10^{\circ}$ & Cristóvão Tezza - O Filho Eterno & 124 & $47 \%$ \\
\hline $11^{0}$ & Guimarães Rosa - Manuelzão e Miguilim & 73 & $28 \%$ \\
\hline $12^{\circ}$ & Manuel Bandeira - Estrela da Vida Inteira & 54 & $21 \%$ \\
\hline
\end{tabular}

Fonte: dados da pesquisa.

Tabela 3: Ranking de obras mais lidas na íntegra na mostra de 2014

\begin{tabular}{|c|c|c|c|}
\hline Ordem & Obra & Leitores & (\%) \\
\hline 10 & Moacyr Scliar - O Centauro no Jardim & 210 & $78 \%$ \\
\hline $2^{\circ}$ & João Simões Lopes Neto - Contos Gauchescos & 198 & $74 \%$ \\
\hline $3^{\circ}$ & Manuel Antônio de Almeida - Memórias de um Sargento de Milícias & 185 & $69 \%$ \\
\hline $4^{\circ}$ & Nelson Rodrigues - Boca de Ouro & 181 & $67 \%$ \\
\hline $5^{\circ}$ & Lya Luft - As Parceiras & 170 & $63 \%$ \\
\hline $6^{\circ}$ & Machado de Assis - Esaú e Jacó & 156 & $58 \%$ \\
\hline $7^{\circ}$ & Fernando Pessoa - Poemas de Alberto Caeiro & 148 & $55 \%$ \\
\hline $8^{\circ}$ & Murilo Rubião - Contos & 143 & $53 \%$ \\
\hline 90 & Gregório de Matos Guerra - Seleta & 137 & $51 \%$ \\
\hline $10^{\circ}$ & Jorge Amado - Terras do Sem Fim & 129 & $48 \%$ \\
\hline $11^{\circ}$ & José Saramago - História do Cerco de Lisboa & 94 & $35 \%$ \\
\hline $12^{\circ}$ & João Cabral de Melo Neto - A Educação pela Pedra & 88 & $33 \%$ \\
\hline
\end{tabular}

Fonte: dados da pesquisa.

Tabela 4 - Ranking de obras mais lidas na íntegra na mostra de 2016

\begin{tabular}{|c|c|c|c|}
\hline Ordem & Obra & Leitores & $(\%)$ \\
\hline $1^{0}$ & Tropicalia ou Panis etCircensis & 96 & $71 \%$ \\
\hline $2^{\circ}$ & Machado de Assis - Dom Casmurro & 89 & $66 \%$ \\
\hline $3^{\circ}$ & Nelson Rodrigues - Boca de Ouro & 86 & $64 \%$ \\
\hline $4^{\circ}$ & Lya Luft - As Parceiras & 86 & $64 \%$ \\
\hline $5^{\circ}$ & Aluísio Azevedo - O Cortiço & 81 & $60 \%$ \\
\hline $6^{0}$ & Sergio Faraco - Dançar Tango em Porto Alegre & 68 & $50 \%$ \\
\hline $7^{0}$ & Murilo Rubião - contos & 68 & $50 \%$ \\
\hline $8^{\circ}$ & Fernando Pessoa - coletânea & 59 & $44 \%$ \\
\hline 90 & Jorge Amado - Terras do Sem Fim & 50 & $37 \%$ \\
\hline $10^{\circ}$ & O Amor de Pedro por João - Tabajara Ruas & 47 & $35 \%$ \\
\hline
\end{tabular}

Fonte: dados da pesquisa. 
Deve-se levar em consideração que os rankings de obras mais lidas exibidos nas Tabelas 2 a 4 dizem respeito a listas diferentes, envolvem composições por curso diversas e amostras que não têm o mesmo tamanho. Apesar disso, há similaridades. Em cada ano, há apenas 4 ou 5 títulos que ultrapassaram a casa dos 50\% de leitura integral. Nas três rodadas, a obra menos lida fugia do gênero preponderante da narrativa de ficção em prosa, com obras de poesia de Manuel Bandeira em 2011 e João Cabral de Melo Neto em 2014, mais os Sermões, de Antônio Vieira, em 2016. Não há repetição de títulos entre 2011 e 2014, mas os quatro que constam tanto na lista de 2014 quanto na de 2016 mostram percentagens semelhantes (respectivamente, As parceiras, de Lya Luft, com 63\% e 64\%; Boca de ouro, de Nelson Rodrigues, com 67\% e 64\%; os contos de Murilo Rubião, com 53\% e 50\%; na diferença mais expressiva, Terras do sem fim, de Jorge Amado, com $48 \%$ e $37 \%$ ). As similaridades são importantes por razões metodológicas, porque indicam coerências ao longo das três rodadas. Como se trata de levantamentos não probabilísticos e com amostras de conveniência, não generalizáveis, as semelhanças funcionam como um indicativo informal da relevância dos dados.

É possível notar outros padrões, como a tendência a que as primeiras posições nos rankings sejam de autores clássicos brasileiros (dois títulos de Machado de Assis e um de José Alencar entre os três primeiros em 2011; Memórias de um sargento de milícias em terceiro em 2014; outro título de Machado de Assis em segundo em 2016). Autores contemporâneos consagrados completam as obras mais lidas, como Nelson Rodrigues (quarto em 2014, terceiro em 2016) e Rubem Fonseca (quarto em 2011).

Em se tratando de uma pesquisa no Rio Grande do Sul e a partir de listas que incluíam autores gaúchos, há uma compreensível relevância das obras regionais entre as leituras dos alunos. Como pode ser visto na Tabela 3, entre os cinco títulos de 2014 com $60 \%$ ou mais de leitura estavam três obras gaúchas (O centauro no jardim, de Moacyr Scliar, em primeiro, com 78\%; Contos gauchescos, de João Simões Lopes Neto, em segundo, com 74\%; e As parceiras, de Lya Luft, em quinto, com $63 \%)$. Mas nem todas as obras gaúchas das listas analisadas aparecem em posições tão proeminentes. Porteira fechada, de Cyro Martins, constava no sétimo lugar em 2011, com 56\% de leitores, e $\mathrm{O}$ amor de Pedro por João, de Tabajara Ruas, era o oitavo em 2016, com 35\%.

$\mathrm{O}$ contraste entre autores gaúchos com leituras maiores ou menores dentro do levantamento reproduz em menor escala o observado em outros títulos das Tabelas 2 a 4, com as posições inferiores do ranking em geral ocupadas por obras com complexidade linguística ou temática (em 2011, Manuelzão e Miguilim, de Guimarães Rosa, com 28\% de leitores e Estrela da vida inteira, de Manuel Bandeira, com 21\%; em 2014, História do cerco de Lisboa, de José Saramago, com 35\% de leitores e A educação pela pedra, de João Cabral de Melo Neto, com 33\%; em 2016, A noite das mulheres cantoras, de Lídia Jorge, com 31\% e os Sermões de Pe. Antônio Vieira com 30\%).

Aqui o exercício epistemológico de triangulação é interessante para contextualizar. Como visto, nas Tabelas 2 a 4 a leitura menor de obras mais complexas aparenta ser um padrão, já que se repete em 2011, 2014 e 2016. Isso não quer dizer, contudo, que as obras estejam sendo rejeitadas pelos alunos por motivos estilísticos, nem permite a inferência, intuitivamente cabível, de que a literatura mais elaborada não agrade aos estudantes. As entrevistas semiestruturadas da fase qualitativa oferecem aprofundamento.

\section{Depoimentos de leitura}

A estudante $\mathrm{COMP} 313^{5}$ era uma grande leitora, acostumada a ler tanto autores de ficção científica quanto clássicos da literatura brasileira e mundial. Leu Guerra e paz e se disse fã de Lya Luft. "Segunda geração romântica... Gosto muito de ler também Castro Alves, gosto bastante, essa galera. Gosto muito de mal do século". COMP313 leu 11 dos 12 livros da lista da UFRGS em 2016 e acertou 24 de 25 questões da prova de Literatura do Vestibular. Apesar de

\footnotetext{
${ }^{5}$ Ao longo da pesquisa, para preservar o anonimato dos respondentes, mesmo na rodada qualitativa, foi adotado um sistema de referenciação por código para nomear os entrevistados. As letras do código indicam o curso do aluno, o primeiro algarismo a rodada e os dois últimos a ordem na tabulação do aluno naquele ano.
} 
acostumada com os livros, entretanto, a única obra que não leu das indicadas foi, justamente, uma das duas menos lidas naquele ano. "Eu só não li A noite das mulheres cantoras, porque aí a professora disse que era muito chato esse tipo de literatura. Daí, eu, bah, não vou ler [risos]".

Da rodada de 2014, o estudante de Letras de 22 anos LET213 leu dez títulos da lista. Um dos que não leu era História do cerco de Lisboa, de José Saramago, uma das duas obras menos lidas daquele ano. LET213 falou sobre os critérios da escolha:

Ah, foi os que eu... Eu fui lendo assim... Acho que era mais... Que achava mais tranquilo de ler, assim, tipo, a peça, depois os contos, assim. Fui indo nessa ordem, assim. Daí, depois, sei lá, li o Jorge Amado, que era um autor que eu gostasse, que tinha curiosidade, daí os que eu sabia que eram mais difíceis, assim. Tipo, o Saramago, eu acabei não lendo, porque eu deixei para o final. Se desse tempo, assim. ${ }^{6}$

Mesmo alunos acostumados aos livros e que leram quase todos os títulos da lista, como COMP313 e LET213, podem, então, ter adotado a estratégia pragmática de adiar ou mesmo suspender a leitura de obras para as quais pensaram que poderiam ter que dedicar mais tempo. Interessante notar que, no caso da estudante de computação, isso aconteceu inclusive a partir de orientações de um professor. E LET213 fez uma programação para ler José Saramago "se desse tempo", o que acabou não acontecendo.

A questão do tempo, compreensível no contexto de alunos em preparação para o vestibular que também podem estar sujeitos a demandas adicionais como o ensino médio ou as provas do Enem, foi mencionada por mais de um entrevistado como um dos parâmetros. BIO317, aluna de Biologia de 17 anos, quando perguntada como escolheu os cinco títulos da lista que leu para o vestibular, respondeu: "Geralmente... geralmente por escolha própria. Às vezes eu não me interessava pelos livros, ou às vezes eu realmente não tinha tempo de ler os livros que eu queria ler". PP307, estudante de Publicidade de 20 anos, leu sete títulos da lista: "Mm... Eu acho que por extensão, eu escolhi eles porque eram mais rápidos de ler primeiro. E também porque... Eu achei eles mais fácil nas lojas também, porque eram mais em conta, eu acho. E... E acho que é isso". A estudante de Jornalismo JOR307, 18, leu seis títulos: "O que tava no cursinho, ou que eu tinha mais interesse de ler, por exemplo. Esse das Parceiras, eu quis ler porque tinham falado muito bem, O cortiço também". Ela variou suportes de leitura, lendo tanto em impresso quanto xerox, computador e celular. Sobre isso, disse que "tentava fazer de formas diferentes, porque não tinha tempo de ler todos os livros".

Uma síntese deste gênero de resposta, que fala do tempo e das escolhas dos estudantes, é o que disse JOR311, estudante de Jornalismo de 19 anos:

Eu... Eu peguei os que, digamos [risos], eles diziam que era mais fácil, assim. E os que deu tempo, sabe, que aí os outros era meio que escolher entre ler os livros e focar em outras matérias que tinha mais dificuldade. Daí eu peguei e li os que deu, assim, e os que eles disseram que era mais fácil, e os que eu não consegui ler eu li resumo, tá?

São pontos recorrentes, nos trechos de entrevistas mostrados acima, tanto as alusões à premência do tempo quanto as estratégias de escolha dos títulos baseadas em rapidez ou facilidade. É um traço comum interessante, também, a presença de um componente social, ao qual JOR311 alude quando fala que leu "os que eles disseram que era mais fácil", ou quando JOR307 diz que "quis ler porque tinham falado muito bem". COMP313 já havia pautado sua escolha por uma indicação de professor. A transmissão oral de conhecimento (no caso, sobre as obras mais rápidas ou fáceis para ler) é própria do contexto educacional, tanto em cursinhos preparatórios quanto no ensino médio do qual são egressos os estudantes. Mas além dos ensinamentos dos professores, também pode estar presente uma relação, ainda que discreta, de autoridade, assim como a reação a ela. Isso foi notado discretamente até mesmo na própria relação dos entrevistados com o pesquisador, na forma das pequenas hesitações e gaguejos de

\footnotetext{
${ }^{6}$ As transcrições procuraram manter, sem edições, as pausas, hesitações e repetições dos respondentes. O conteúdo não verbal das entrevistas traz informações úteis, como, no caso de LET213, possivelmente um embaraço ao prestar contas de suas opções de leitura no vestibular.
} 
BIO317 e PP307, ou, mais nitidamente, na formulação quase de justificativa com a qual JOR311 encerra uma frase: "e os que eu não consegui ler eu li resumo, tá?"

Outro fator relevante descortinado pelas entrevistas qualitativas é que algumas escolhas não resultaram de opções dos estudantes, mas foram determinadas pela disponibilidade. PP307, citada acima, mencionava que o fato de ter encontrado alguns livros mais facilmente nas lojas, ou por preço menor, foi um dos determinantes para a escolha dos títulos que leu. COMP324, estudante de Computação de 19 anos, leu seis livros:

É que, assim. Eu tinha em meta ler quase todos eles pelo livro [rindo]. Só que... acabei não conseguindo todos, então eu li os que eu tinha. Meu irmão tinha O cortiço, o Dom Casmurro, e eu peguei emprestado dele, e... eu não queria pegar emprestado de... pessoal, ia acabar demorando pra devolver. E então, eu acabei optando pelos outros PDFs, ou... ou mesmo às vezes eu pegava na biblioteca na escola, só que... como eu tinha que devolver [rindo], e eu não me tocava das datas, acabei optando pelo PDF mesmo.

O que COMP324 descreve é uma estratégia de obtenção dos títulos, que passa por sua conveniência pessoal e pelas suas conexões sociais, da família à escola. Também envolve variância de suportes. É uma situação compartilhada. DIR219, estudante de Direito de 17 anos entrevistado na rodada de 2014, leu três títulos da lista e explicou: "Eu... não escolhi eles. Eram os que eu tinha que ler para a escola, antes de eu começar a fazer cursinho. Porque até eu fazer cursinho, eu lia todos os livros que tinha que ler para a escola. E esses eu tive que ler no segundo ano".

Os cursinhos pré-vestibular também ajudaram a determinar escolhas de leitura para alguns dos alunos. PSI220, de 19 anos, da rodada de 2014, empregou uma variedade de suportes para ler oito títulos da lista, entre livro, xerox e computador: "Muitos livros o próprio cursinho dava alguns xerox. Tem na internet também alguns, e alguns, hã, alguns, eu lembro que o meu irmão me deu, que o meu irmão fez vestibular antes, e algumas leituras eram parecidas".

JOR307 também diversificou suportes:

Teve alguns que eu li em livro impresso e alguns no computador. O cortiço eu li no celular [...] porque eu consegui baixar ele no telefone, e eu lia no ônibus, ou esperando as pessoas chegarem, se eu estivesse esperando alguém... Foi uma leitura em vários lugares, assim. O celular é mais fácil de carregar, né?

Em alguns casos, a leitura de um mesmo título passou por mais de uma plataforma, conforme as opções que o estudante obteve. JOR304, 18 anos, leu uma obra recomendada de Fernando Pessoa parcialmente em xerox e parcialmente no computador:

É que assim, eu tinha em xerox, hã, eu acho que eu tinha da escola, e aí eu tinha ele... Sei que eu consegui na biblioteca e também de cursinho, então eu tinha xerox de cursinho e escola, e o livro tava na biblioteca também, daí eu acho que fui lendo meio que os dois juntos, assim.

A aluna detalhou como teve acesso aos sete títulos do vestibular que leu:

É assim. Hã, alguns a gente tinha, que eu tive que ler no ensino médio para a leitura, tipo, dã, de disciplinas da escola, né? E aí algunss nossos professores conseguiam pra gente xerox de materiais deles, que daí a gente não conseguia por exemplo o livro na biblioteca, não tinha na biblioteca do município nem na biblioteca da escola, e eles passavam xerox pra gente, alguns eles não conseguiam xerox nem no livro físico, aí eles conseguiam algum link de, do livro on-line. E alguns a própria escola disponibilizava no, na biblioteca, daí assim a gente tinha acesso tipo ao livro mesmo físico.

Essa conjunção de suportes e procedências, que alguns alunos empregavam para ter acesso aos títulos, também podia, em outros casos, ser usada para a própria não-leitura das obras. COMP313, que leu onze livros, substituiu por resumos a única leitura de título que não fez: "Eu li todos os resumos possíveis, e um monte de coisa na internet, tal". PP222, estudante de Publicidade de 19 anos entrevistado na rodada de 2014, não chegou a ler na íntegra qualquer título da lista do vestibular. Sobre sua preparação para as provas, contou: "Eu tinha um material, eu tinha os dois livros que eram de resenhas e resumos, que foi, eu não lembro qual instituição foi feita. Mas eu comprei na época e li só eles". DIR215, 18 anos, da rodada de 2014, leu seis títulos da lista. Perguntado se estes haviam sido aqueles aos quais teve acesso, explicou: 
Não, eu tinha todos, e eu tinha aula de literatura no colégio, a gente tinha uma aula de literatura muito boa, com materiais de estudo sobre eles. Então, eu... os outros eu até cheguei a começar, mas como estava meio... meio atrapalhado com o tempo, eu acabei... interrompendo pela metade.

Tanto no caso das opções de leitura quanto na não-leitura, como se nota, houve diversas opções e percursos, às vezes passando por mais de um suporte ou plataforma e com apoio ou aconselhamento de professores, cursinhos e familiares. Pode-se notar, pela variedade das estratégias de estudo, como o indicador das listas de vestibular funciona como uma janela para que se entreveja a dinâmica sociocultural do relacionamento dos estudantes com o ambiente no qual estão inseridos, e onde vão buscar seu material de estudo e suas táticas de leitura ou não-leitura.

\section{Analisando dados sobre acesso}

A pesquisa observou que a aproximação dos alunos ao material literário foi marcada, nas turmas amostradas, pela grande alternância de suportes e vias de contato. O Gráfico 2, a seguir, mostra um comparativo entre os percentuais de acesso aos diferentes suportes de conteúdo usados pelos estudantes para contato com a lista de vestibular nas rodadas de 2011, 2014 e 2016.

Gráfico 2 - Comparativo de percentuais de suporte empregados (2011 e 2016)

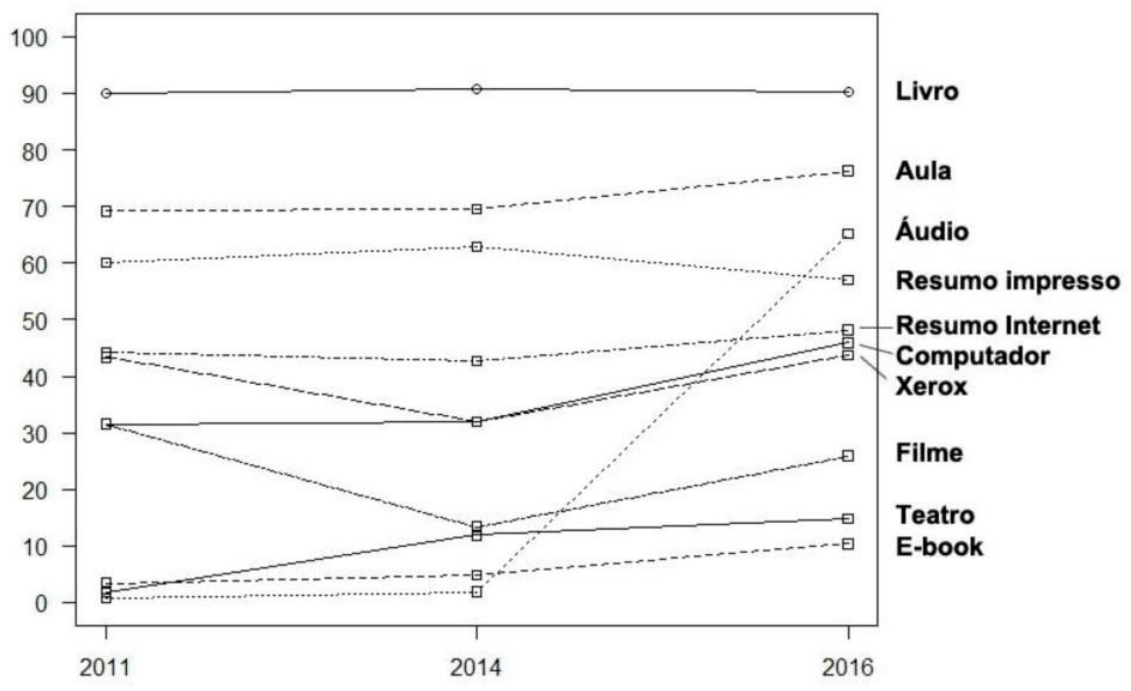

Fonte: dados da pesquisa.

O Gráfico 2 traz dados sobre todas as formas de contato com as obras da lista de vestibular assinaladas pelos estudantes. Isso inclui modalidades de resumo e contato parcial. Os alunos eram orientados a marcar em uma ficha todas as categorias que haviam adotado para cada título, independentemente se haviam realizado a leitura integral do texto ou não. Fica evidente a preponderância absoluta e isolada do livro impresso, a mais estável das plataformas ao longo do período estudado. Compreensivelmente, em se tratando de um contexto estudantil, categorias como resumos e aula aparecem também em destaque. Há especificidades advindas da própria evolução das listas da UFRGS, como o aumento súbito da categoria de áudio em 2016, por conta da inclusão, na relação de obras daquele ano, de um álbum musical (Tropicalia, conforme pode ser visto na Tabela 4, por sinal a obra que liderou o ranking de acesso entre os respondentes naquele ano). O Gráfico 2 ilustra, entre outras coisas, a complexidade da malha de contato dos estudantes com o texto literário, que passa por múltiplas plataformas. Ainda que se trate de um contexto preparatório ao vestibular, com uma forte dimensão normativa, há indicativos de que os estudantes também lançam mão de diversidade de suportes no contato 
com obras literárias feito de forma eletiva, por prazer ou fruição. Isso foi observado qualitativamente nas entrevistas, que também abrangeram as atividades de lazer.

Um exemplo é o caso do estudante de Ciência da Computação COMP324, que tinha 19 anos ao responder à entrevista. Já ao comentar a preparação para o vestibular, apontou que tinha a intenção de ler todos os títulos em livro impresso, mas não conseguiu todos, então leu alguns emprestados, outros em xerox e alguns também em arquivo eletrônico por conveniência de acesso. Sobre sua leitura pessoal, ele expressou um comportamento parecido:

De lazer, eu leio só pelo Kindle Google Books, lá que a gente entra no celular e etc. Mas... Hã, é que o problema é conseguir os livros, tá ligado? [risos, e rindo] Porque o problema é ir lá na loja e comprar. Às vezes a gente fica com preguiça e eu prefiro comprar pela internet, é tudo mais fácil, mais rápido.

Sobre as leituras que preferia, COMP324 disse "Eu gosto mais de, esses tipo Sherlock Holmes, assim, de suspense. Um pouco de romance eu também gosto, sei lá". Seus interesses de lazer em geral passavam por outras plataformas, como vídeo e quadrinhos esta última em conjunção com cinema, já que comentou que gostava de assistir a filmes baseados em super-heróis que tinha lido. Perguntado se tinha algum comentário sobre seus hábitos de estudo, leitura ou cultura em geral, disse o seguinte:

Olha, é difícil explicar, porque... É que tem muita gente que prefere o livro, né? Mas eu sou tipo, eu gosto dos dois, assim. O que tiver mais acessível eu acabo pegando. Eu acabo optando pelo livro eletrônico mesmo porque é mais acessível, mais fácil, não precisa sair de casa, é só comprar pela internet mesmo. Mas... o livro tem uma coisinha diferente, eu não sei por que, mas... Pegar o livro é até melhor, até.

Assim como COMP324, a estudante de Biologia BIO313 também refletiu sobre seus próprios hábitos de leitura durante a entrevista. Ela contou que na faculdade sentia falta das aulas de literatura do ensino médio: "Porque agora o meu curso é muito natureza, né, então não tem nada dessas coisas. Então eu sinto um pouco de falta. Mas tou tentando compensar, com este cursinho que estou fazendo agora, e tal". O curso a que se referia era de literatura russa. Ao final da conversa telefônica, ela sintetizou sua trajetória pessoal de leitura:

Acho que é interessante comentar que eu sempre tive esse hábito, né. Eu fui estimulada desde bem cedo a começar a ler, e foi uma coisa que ficou comigo, assim. A minha mãe, por exemplo, ela não lê nada, só lê coisa relacionada ao trabalho dela, acho que a única vez que ela leu um livro porque ela queria ler já faz uns quinze anos. Pra mais [risos]. E eu gosto de ter esse hábito assim. Às vezes é meio difícil conciliar com as outras coisas, porque é muita coisa pra fazer, né? Mas sempre tem um tempinho, e aí tem um tempinho pra ler, e tal, e ficar pensando naquilo, eu gosto bastante de livros de ficção, assim, ou de realismo fantástico, de contos, assim, sabe? E... Murilo Rubião foi outro que eu gostei bastante. No vestibular, de contos. Mas... Eu gosto desse tipo de leitura. E eu acho legal ter um tempo pra isso, e tal, e quero que esse hábito permaneça comigo até o fim da minha vida.

Interessante, nesta declaração de BIO313, é sua consciência dos próprios hábitos de leitura e mesmo de suas estratégias de estudo, coincidindo em parte com apontamentos de COMP324. Deve-se levar em conta a reflexão epistemológica de que ambas as entrevistas, como em geral acontece com esta implementação metodológica, consistem em construções narrativas dos entrevistados e, portanto, são discursos elaborados tendo por base um pressuposto dos respondentes em relação às expectativas do pesquisador. Ainda assim, as declarações são compatíveis com os dados obtidos na fase quantitativa, apresentados nos gráficos e tabelas.

Embora esses resultados sejam apenas parte do volume de informações captado pela pesquisa, esta amostra é suficiente para discutir o problema do presente artigo. A seção a seguir busca uma síntese analítica. 


\section{Considerações finais}

O presente artigo deriva de uma pesquisa originária da área de Comunicação, por isso se encontra nativamente preocupada com a questão multiplataforma do ponto de vista do suporte informacional. $\mathrm{O}$ indicador escolhido das listas de vestibular, entretanto, aproximava o trabalho das áreas de Literatura e Educação, motivo pelo qual é ensaiada, aqui, uma interpretação dos dados centrada na relação dos leitores com o texto literário. Uma das questões observadas na revisão teórica preparatória, justamente, diz respeito à pers pectiva de integração dos resultados. Em muitos casos, conceituações sobre modos de leitura são erguidas pelos autores a partir de estudos de caso ou análises de conteúdo, frequentemente realizados na esfera de produção. É o que acontece, no referencial teórico reproduzido neste artigo, com as observações de Gomez (2008) e Villaça (2010). Birkerts (2006) constrói um modelo que contempla a apropriação por parte dos leitores, porém incorre em um reducionismo com viés determinista ao abraçar o conceito, familiar a McLuhan (1972), de que a multiplicação de meios tende a afetar a profundidade ou capacidade de imersão. Mesmo Thompson (2008) simplifica a questão particular da leitura quando observa que narrativas tendem a ter menor portabilidade em termos de suporte de conteúdo.

Mesmo descontando a representatividade reduzida da amostra de estudantes observados na pesquisa e o caráter fortemente normativo do contexto de apuração, os dados de leitura, estudo e apropriação apresentados na seção anterior delineiam um quadro muito mais complexo do que seria de se supor a partir de algumas das posições indicadas no referencial teórico. $O$ Gráfico 2, que apresentava o panorama geral de suportes de contato utilizados pelos alunos tanto para contato com o texto integral das obras do vestibular quanto para acesso a resumos, pode, à primeira vista, evidenciar uma instância do que Birkerts (2006, p. 138) chama de "novos níveis de conexão e integração". Porém, como apontam as experiências de alguns dos alunos entrevistados, notadamente COMP313 e BIO313, que se identificavam como grandes leitoras, a simples multiplicação de meios de contato com o texto literário não chega a configurar o quadro mais pessimista desenhado pelo autor, já que ambas relatam alternância de suportes e até substituição por resumos, mas ao mesmo tempo descrevem experiências imersivas.

O artigo atual não mobiliza um referencial teórico extensivo, mas dialoga com autores que contemplam multiplicidade de meios e suportes de leitura para evidenciar um contraste que emergiu dos resultados da pesquisa. Algumas fontes consultadas, como Gomez (2008) e Villaça (2010), tendem a privilegiar estudos da esfera de produção, outras, como Thompson (2008) e Birkerts (2006), estabelecem diferenciações valorativas entre as plataformas. São modelizações que podem ser constituídas de grande complexidade interna e riqueza de insights. Porém, tanto em um quanto em outro caso não se dá plenamente conta da amplitude da margem de escolha por parte dos leitores observada no trabalho de campo da pesquisa.

Desde a estudante JOR307, que mesclou várias plataformas e procedências para ler os títulos da lista de vestibular, até COMP324, que mesmo por lazer faz sempre a opção de leitura mais acessível, estudantes relataram toda uma gama de trajetos de apropriação do texto literário, que, como ilustrava o Gráfico 2, desenha um mapa complexo. Não é possível reduzir as experiências de leitura aferidas pela pesquisa a um modelo unificado porque não foram observadas regras distributivas padronizadas. As soluções de leitura, até onde foi possível verificar, tendem a ser paroquiais, específicas. As trajetórias de leitura passavam por plataformas ou suportes mais adequados, possíveis, disponíveis ou preferidos caso a caso. O mesmo, paralelamente, pôde ser observado em relação ao conteúdo de leitura, de uma forma mais ampla.

A pesquisa trabalhou principalmente com leitura normativa, ao pautar sua amostra pela apropriação das leituras da lista de vestibular da UFRGS. Porém, ao estender a observação para os lados, inquirindo os estudantes entrevistados sobre outros hábitos de lazer, pôde observar que o padrão, ou não padrão, de soluções pessoais de leitura se estende a toda a esfera comunicacional dos alunos, e mesmo conforma sua relação com a experiência de fruição de literatura. COMP313 menciona que gosta da "segunda geração romântica", adotando a nomenclatura dos cursos do ensino médio para situar seu gosto pessoal de leitura; JOR304 leu 
Fernando Pessoa passando de xerox para livro emprestado e texto eletrônico, ao sabor da conveniência do momento. Outros alunos ouvidos pela pesquisa também relataram experiências diversas que envolviam trânsito entre plataformas, como uma jovem que se interessava por livros ao ver trailers no cinema de filmes baseados em obras literárias, depois se apressava a lê-los antes da estreia para ter tido contato prévio com o material original do autor antes de assistir à adaptação. Um estudante contou que leu livros para tentar entender um seriado de televisão baseado neles. Já não se trata, nestes casos, de uma preferência por um meio ou por outro, mas de uma experiência que passa pela conjugação deles. A experiência imersiva, que Birkerts (2006) temia ser perdida após se perder o contato com o livro, passa a ser, nestes casos, uma imersão no próprio conjunto de suportes.

É a partir destes elementos da observação empírica que é possível esboçar uma contribuição para um modelo de leitura que contemple a apropriação do texto literário em um contexto mais amplo. A própria constituição das listas da UFRGS, como pôde ser visto nas Tabelas 2 a 4, traz em si mesma uma evolução no conceito de obra literária, já que passaram a ser incluídos álbuns musicais na lista de títulos recomendados. Como se nota pelos índices de leitura, esta mudança foi rapidamente apreendida pelos estudantes, que elevaram esta obra à posição de mais acessada naquele ano (Tabela 4).

Tanto na área de Comunicação quanto na de Teoria da Literatura, mesmo quando se abandona o amplo domínio das análises de conteúdo (baseadas na esfera da produção), há uma tradição de hermenêutica que, ainda que contemple a figura do leitor, se baseia na apropriação de conteúdo. Mas a margem de liberdade dos leitores, de acordo com o estudo empírico realizado, ainda que em uma esfera limitada, se estende para muito além dos domínios interpretativos. Os estudantes observados relataram que tiveram seu interesse por obras literárias despertado por uma variedade de fontes, de trailers de cinema a recomendações de colegas ou professores, e por sua vez efetivaram esse contato e a apropriação dos textos através de toda uma nuvem de suportes e plataformas que, por sua vez, podiam ser usados isoladamente ou de forma conjugada. Em certos casos, alunos relataram não o contato físico com as obras, mas o mergulho em toda uma névoa de conteúdo originado por elas. Não se tratou, então, de segurar um livro ou mesmo acessar uma versão eletrônica, mas de adentrar uma nuvem de texto.

Embora sem a pretensão ou o aprofundamento para caracterizar a metáfora da nuvem como um operador conceitual propriamente dito, o presente trabalho buscou oferecer subsídios para imaginar a delimitação de uma eventual categoria de leitura contemporânea entendida nestes termos. A imagem da nuvem do texto funciona para congregar dados observacionais como a multiplicação de suportes que aparentemente substitui, em certos casos, uma referência de suporte unificada - ou, por assim dizer, sólida ou monolítica. E esta metáfora da névoa também busca marcar uma diferença conceitual em contraponto àquele entendimento de certa linha de pensamento teórico que constrói a multiplicação de suportes ou meios como necessariamente oposta à imersão da leitura ou ao aprofundamento no conteúdo. A nuvem do texto, como sugerem os depoimentos e dados aqui apresentados, tem sua própria capacidade de engolfar os leitores. Esta, precisamente, é a bruma que o presente artigo buscou ajudar a compreender.

\section{Referências}

BIRKERTS, Sven (2006). The Gutenberg elegies: the fate of reading in an electronic age. New York: Faber and Faber.

FIDELIS, Ana Cláudia (2008). Do cânone literário às provas de vestibular: canonização e escolarização da literatura. Tese (Doutorado em Linguística Aplicada) - Universidade Estadual de Campinas, Campinas.

GOMEZ, Jeff (2008). Print is dead: books in our digital age. New York: Macmillan.

MACHADO, Arlindo (2002). As mídias são os livros de nosso tempo? In: PERUZZO, Cicilia. A mídia impressa, o livro e as novas tecnologias. São Paulo: Sociedade Brasileira de Estudos Interdisciplinares. p. 109-121. 
McLUHAN, Marshall (1972). A galáxia de Gutenberg: a formação do homem tipográfico. São Paulo: Editora Nacional; Editora da USP.

MORAES, André Carlos (2017). Leitores multiplataforma: o livro em um contexto de múltiplos suportes, a partir da prática de estudantes universitários. Tese (Doutorado em Comunicação e Informação) Universidade Federal do Rio Grande do Sul, Porto Alegre.

THOMPSON, John B (2008). Books in the digital age. Cambridge: Polity.

VILLAÇA, Nízia (2010). Mixologias: comunicação e o consumo da cultura. São Paulo: Estação das Letras e Cores. 